\title{
Preliminary Test Results for Stability and Control Characteristics of a Generic T-tail Transport Airplane at High Angle of Attack
}

\author{
Kevin Cunningham ${ }^{1}$, Gautam H. Shah ${ }^{2}$, Neal T. Frink ${ }^{3}$, Susan N. McMillin ${ }^{4}$, Patrick C. Murphy ${ }^{5}$ \\ NASA Langley Research Center, Hampton, VA, 23681 \\ Frank R. Brown ${ }^{6}$, Patrick J. Hayes ${ }^{7}$, Kamal M. Shweyk ${ }^{8}$ \\ Boeing Research \& Technology, Huntington Beach, CA, 92647 \\ Sudheer N. Nayani ${ }^{9}$ \\ Analytical Services \& Materials, Hampton, VA, 23666
}

\begin{abstract}
Tests of a generic T-tail transport airplane, in flaps-up configuration, were conducted using two wind tunnels, a water tunnel, and computational fluid dynamics. Static force and moment testing, forced oscillation testing and dye flow visualization test techniques were used. The purpose of the testing was to obtain stability and control characteristics for development of a research flight simulator aerodynamic database. The purpose of that database was for assessment of aerodynamic model fidelity requirements to train airline pilots to recognize and recover from full stall conditions. Preliminary results, at initial stall conditions, include: an unstable stall pitch break, and near-neutral roll damping. Preliminary results, at deep stall conditions, include: a potential static longitudinal trim condition at approximately 35 degrees angle of attack, large aerodynamic asymmetries, and localized unstable dynamic stability.
\end{abstract}

\begin{tabular}{llll} 
& \multicolumn{3}{c}{ Nomenclature } \\
BR\&T & $=$ Boeing Research \& Technology & $\mathrm{k}$ & $=$ reduced angular frequency, $\left(\omega L_{-} r e f\right) / 2 V$ \\
$\mathrm{~b}$ & $=$ wingspan & LST & $=$ low-speed tunnel \\
CAST & $=$ Commercial Aviation Safety Team & $L_{-} r e f$ & $=$ reference length \\
CFD & $=$ computational fluid dynamics & M & $=$ Mach number \\
CG & $=$ center of gravity & MRC & $=$ Moment Reference Center \\
$C_{l}$ & $=$ rolling moment coefficient & NAART & $=$ North American Aviation Research Tunnel \\
$C_{m}$ & $=$ pitching moment coefficient & NASA & $=$ National Aeronautics and Space Administration \\
$C_{n}$ & $=$ yawing moment coefficient & NTSB & $=$ National Transportation Safety Board \\
$\mathrm{c}$ & $=$ mean aerodynamic chord & p, q, r & $=$ roll, pitch, yaw body axis rates \\
deg & $=$ degrees & rad & $=$ radian \\
FAA & $=$ Federal Aviation Administration & $\mathrm{S}$ & $=$ wing area \\
FVWT & $=$ Flow Visualization Water Tunnel & $\mathrm{SE}$ & $=$ Safety Enhancement \\
GTT & $=$ Generic T-tail Transport & $\mathrm{sec}$ & $=$
\end{tabular}

\footnotetext{
${ }^{1}$ Senior Research Engineer, Flight Dynamics Branch, MS 308, AIAA Senior Member.

${ }^{2}$ Senior Research Engineer, Flight Dynamics Branch, and Manager, TASA, MS 308, AIAA Senior Member.

${ }^{3}$ Senior Research Engineer, Configuration Aerodynamics Branch, MS 499, AIAA Associate Fellow.

${ }^{4}$ Research Aerospace Engineer, Configuration Aerodynamics Branch, MS 499.

${ }^{5}$ Senior Research Engineer, Dynamic Systems \& Controls Branch, MS 308, AIAA Associate Fellow.

${ }^{6}$ Aerospace Engineer, Boeing Research \& Technology, M/S H017-D334, AIAA Member.

${ }^{7}$ Aerospace Engineer, Boeing Research \& Technology, M/S H017-D334.

${ }^{8}$ Flight Engineering Manager, Boeing Research \& Technology, M/S H017-D334, AIAA Associate Fellow.

${ }^{9}$ CFD Manager, Analytical Services \& Materials Inc., 107 Research Drive, AIAA Associate Fellow.
} 


$\begin{array}{ll}\text { TASA } & =\text { Technologies for Airplane State Awareness } \\ \text { TetrUSS } & =\text { Tetrahedral Unstructured Software System } \\ \text { TER, TEL } & =\text { trailing edge right, trailer edge left } \\ \text { TEU, TED } & =\text { trailing edge up, trailing edge down } \\ \mathrm{V} & =\text { velocity } \\ \alpha & =\text { angle of attack } \\ \dot{\alpha} & =\text { angle of attack rate of change }\end{array}$

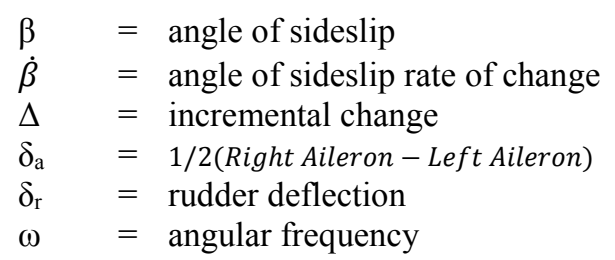

\section{Introduction}

In-flight loss-of-control has historically been a major contributor to the fatal accident rate of commercial transport airplanes ${ }^{1}$. A key intervention strategy that aims to reduce the occurrence of loss-of-control accidents is the improvement of flight simulations to allow for more accurate representation of stalls, loss-of-control, and upset scenarios. The potential uses for the improved simulations include control law analysis, advanced flight display design, mishap investigation, engineering support, and training for recognition and recovery from full stall conditions. The National Aeronautics and Space Administration (NASA) published research on this topic in $2002^{2}$. At that time, a NASA/Boeing partnership, conducting research under NASA's Aviation Safety Program, performed extensive aircraft accident analysis, simulation technology analysis, ground-based aerodynamic testing, and flight simulation development to address the potential for improving transport airplane simulations for use in stall and upset conditions ${ }^{3}$. The focus vehicle for that configuration was a transport airplane with a conventional horizontal tail (mounted low relative to the vertical tail, as opposed to a T-tail configuration).

In 2009, the National Transportation Safety Board (NTSB) investigated a fatal mishap involving in-flight loss of control of a twin engine turbo-prop commercial transport airplane. The NTSB determined the probable cause of that mishap to be an inappropriate response to a stall warning system which resulted in an aerodynamic stall from which the airplane did not recover. In their investigative report ${ }^{4}$, the NTSB cited research by NASA/Boeing and others relating to modeling and simulation of stalled flight conditions. One of the report's recommendations (A-10-24) called for defining simulator fidelity requirements and addressing other requirements to support full stall recovery training during flight simulator training.

Secondary to publication of NTSB recommendation A-10-24, a public law (111-216) was passed in 2010, which requires stall training for all part 121 air carriers. To meet the requirements of that law, the Federal Aviation Administration (FAA) developed rules and regulations which will result in full stall simulator training beginning in $2019^{5}$. During this developmental phase, the FAA has investigated ${ }^{6}$ fidelity requirements for aerodynamic models used to simulate stall characteristics. That investigation focused on several stall models representing an airplane with wing mounted engines and a conventional, low, horizontal tail. Expanding research efforts to include the study of stall model fidelity pertaining to airplanes with T-tail, aft twin-engine configurations was identified within a safety enhancement element by the Commercial Aviation Safety Team (CAST).

CAST is a government-industry partnership with a strategy to achieve their goal of reducing commercial aviation fatality risk. CAST working groups use accident analysis to identify plans for potential changes to prevent accidents. These formally adopted plans take the form of Safety Enhancements (SE). SE-209 is the specific CAST researchbased Safety Enhancement which includes an element to investigate flight dynamics models of a T-tail airplane with aft twin engines. The research presented in this paper is intended to contribute toward the goals of SE-209.

This research is being conducted under Technologies for Airplane State Awareness (TASA), a subproject within the NASA Airspace Operations and Safety Program's System-Wide Safety Project. In partnership with NASA, Boeing Research \& Technology (BR\&T) has conducted testing of a Generic T-tail configuration (GTT) as part of research and development of advanced modeling and uncertainty quantification methods for flight dynamics. Tunnel tests were conducted in the NASA Langley Research Center 12-Foot Low-Speed Tunnel (12-Foot LST), the Boeing North American Aviation Research Tunnel (NAART), and the Boeing Flow Visualization Water Tunnel (FVWT). Knowledge gained from the tunnel tests was bolstered by computation fluid dynamics studies performed with the NASA Tetrahedral Unstructured Software System (TetrUSS). 
Not discussed in this paper are many other aspects of the overall SE-209 research element: development of propulsion system models, piloted simulator systems models, simulator displays, simulator hardware interfaces, and evaluations during piloted simulator sessions. This paper will focus on preliminary ground-based test results used to obtain the stability and control characteristics suitable for the development of a simulator flight dynamics model.

To stay within the constraints of budget, workforce, and schedule this research has used a generic airplane model, focused on a single clean wing (flaps/slats up) configuration, and used low-cost tunnels. As a result, the tunnel results were obtained at low-speed and low chord-based Reynolds Numbers $(\leq 270,000)$. Computational fluid dynamics (CFD) methods were used in this work to help understand the effects of Reynolds number on key stability characteristics.

\section{Model Description}

The generic T-tail configuration used in this work was derived from a remotely piloted airplane configuration that was designed by NASA and Area-I, Inc. The design was intended to be a $15.8 \%$ scaled model of a generic short to medium range twin-jet transport with aft mounted engines and a T-tail. The remotely piloted vehicle was built by Area- $\mathrm{I}^{7}$ and delivered to NASA for use in loss-of-control-prevention research ${ }^{8}$ being conducted under the NASA Aviation Safety Program. Due to NASA programmatic re-planning, that vehicle was not flown. A modified variant of the remotely piloted airplane design was used as the basis for a theoretical full scale configuration and the wind tunnel models.

The full scale airplane aerodynamic reference geometry is shown in Table 1 and the wind tunnel model scale factors (relative to full scale) are shown in Table 2. The GTT configuration geometry and control layout is shown in Figs. 1 to 4. In Figs. 5 and 6, the model is shown, mounted in the 12-Foot LST with controls deflected. The moment reference center (MRC) is located at the $25 \%$ mean aerodynamic chord location. A different model was constructed for each test to the maximum scale practical for each facility. The models used in these tests were constructed using inexpensive rapid prototyping construction techniques. The models for the 12-Foot LST and FVWT were both constructed using polycarbonate three dimensional printing techniques. The model used in the NAART test was constructed using a stereo lithography process. Flow-through engine nacelles were used on all three models. Propulsion effects were not tested during these tunnel entries.

The models used in the 12-Foot LST and NAART tests were constructed with individual control surfaces parts so the effect of control surface deflections could be studied. Control surface deflection ranges are shown in Table 3. It should be noted that the flaps on this configuration are plain flaps. Since that flap geometry was not considered to be representative of a transport configuration, the results of flap effect testing are not reported in this paper.

Table 1. Aerodynamic reference dimensions for the full-scale geometry.

\begin{tabular}{|c|c|c|}
\hline $\begin{array}{c}\text { Aerodynamic } \\
\text { Reference }\end{array}$ & Symbol & $\begin{array}{c}\text { Full Scale } \\
\text { Dimension }\end{array}$ \\
\hline Mean Aerodynamic Chord & $\mathrm{c}$ & 11.07 feet \\
\hline Wingspan & $\mathrm{b}$ & 75.98 feet $^{2}$ \\
\hline Wing Area & $\mathrm{S}$ & 754.32 feet $^{2}$ \\
\hline
\end{tabular}

Table 2. Scale factors of test facility models.

\begin{tabular}{|c|c|}
\hline Test Facility & Model Scale Factor \\
\hline NASA 12-Foot LST & 0.057 \\
\hline Boeing NAART & 0.020 \\
\hline Boeing FVWT & 0.019 \\
\hline
\end{tabular}

Table 3. Control surface deflection ranges.

\begin{tabular}{|c|c|}
\hline Control Surface & Deflection Range, degrees \\
\hline Elevator & -20 (TEU) to +20 (TED) \\
\hline Stabilizer & -10 (TEU) to +5 (TED) \\
\hline Spoilers & 0 to 60 (TEU) \\
\hline Ailerons & -25 (TEU) to +25 (TED) \\
\hline Rudder & $-30($ TER) to +30 (TEL) \\
\hline Flaps & 0 to 60 (TED) \\
\hline
\end{tabular}




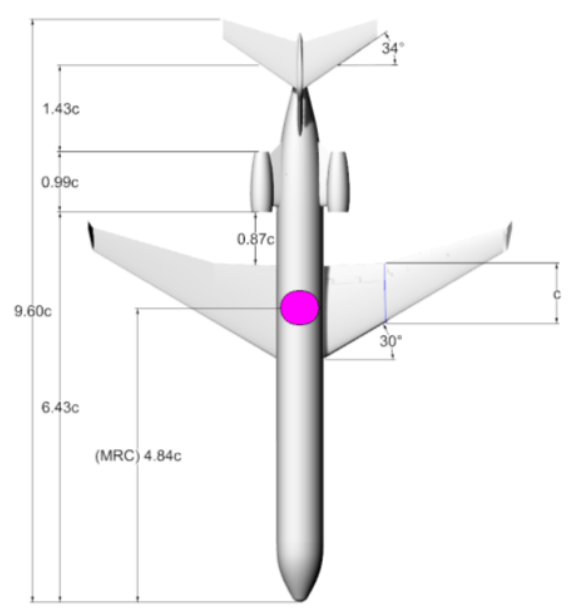

Fig. 1 A GTT dimensional drawing is shown in the plan view.

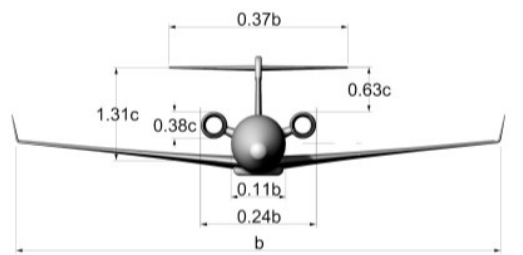

Fig. 3 A GTT dimensional drawing is shown from a front perspective.

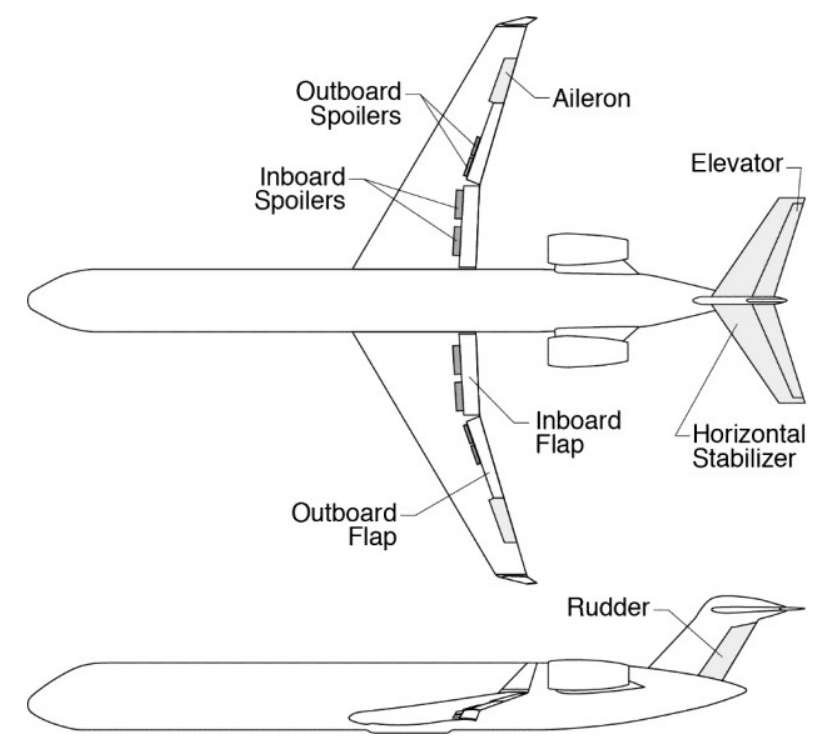

Fig. 2 A GTT sketch showing control surface arrangement.

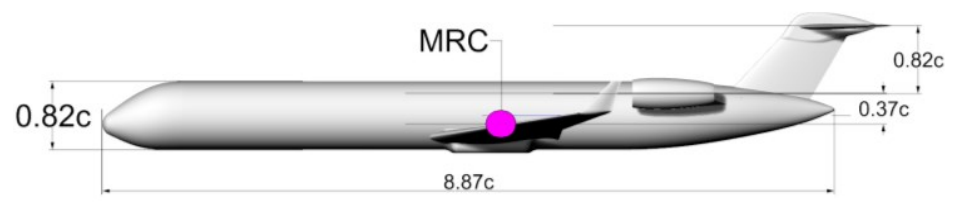

Fig. 4 A GTT dimensional drawing is shown from a left side perspective.

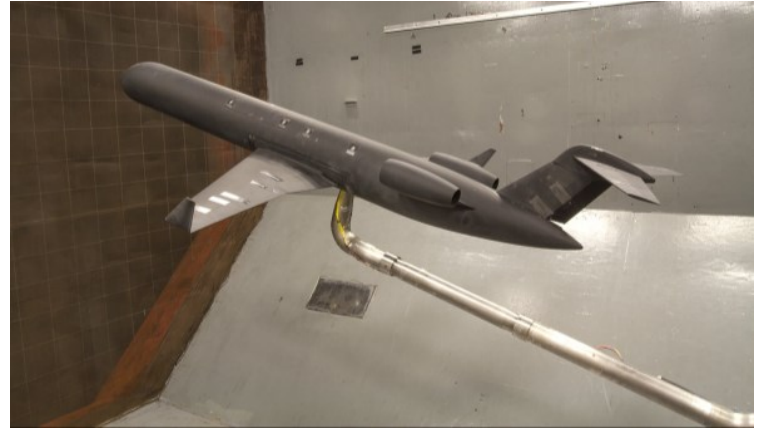

Fig. 5 The GTT is shown mounted in the 12-Foot LST. The elevator and rudder surface arrangement is visible.

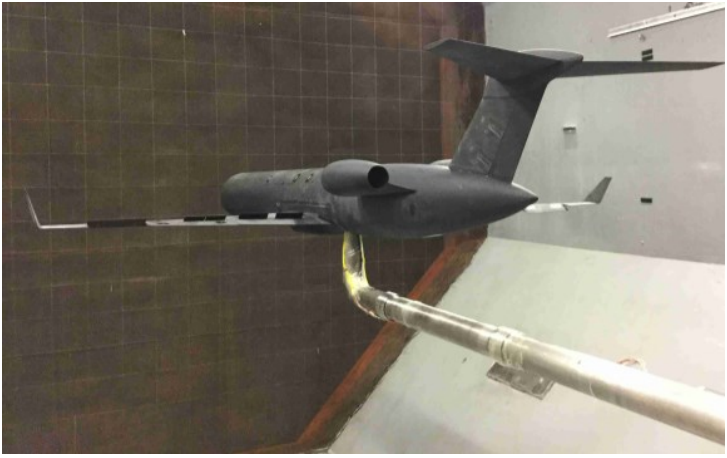

Fig. 6 The GTT is shown mounted in the 12-Foot LST on a bent sting mount. The arrangement of the roll control surfaces (aileron and spoilers) is visible on the left wing. 


\section{Ground Test Capability Descriptions}

The tunnel facilities used in this work are located at NASA Langley Research Center in Hampton, Virginia, and Boeing Research \& Technology (BR\&T) in Huntington Beach, California. Static and forced oscillation testing has been conducted at the NASA Langley Research Center 12-Foot Low-Speed Tunnel (12-Foot LST). Static, forced oscillation, and flow visualization testing has been conducted in the BR\&T Flow Visualization Water Tunnel (FVWT). Static force and moment testing has been conducted in the BR\&T North American Aviation Research Tunnel (NAART).

\section{A. NASA Langley Research Center 12-Foot Low-Speed Tunnel}

The 12-Foot LST is an atmospheric pressure, annular-return tunnel enclosed in a 60-foot diameter sphere. The test section is octagonal with a width and height of 12 feet and a length of 15 feet with each octagonal side measuring 5 feet. The maximum operating dynamic pressure, 7 pounds per square foot, corresponds to a Reynolds number of approximately 490,000 per foot. Tests of the GTT were generally performed at a dynamic pressure of 4 pounds per square foot (chord based Reynolds number of 250,000).

The nature of the work conducted in the 12-Foot LST is principally exploratory research in the area of high angle of attack stability and control characteristics of new configuration concepts. The scope of investigations is generally broad. Because the tunnel is used strictly for low-speed testing, aerodynamic loads are relatively low, which allows models to be light and constructed of inexpensive materials.

The GTT model was mounted through the bottom of the fuselage on a bent sting which was attached (via a motor capable of rolling the sting for forced oscillation testing) to a C-strut. The bottom mount approach avoided aft end flow distortion that could occur if a straight sting was used to mount via the model aft end. The bent sting allowed body axis alignment with the oscillation axis during roll-axis forced oscillation testing. The sting is moved along the $\mathrm{C}$-strut to change the angle of attack from $-10^{\circ}$ to $90^{\circ}$, and the strut is rotated about a vertical axis to change the angle of sideslip from $-90^{\circ}$ to $90^{\circ}$. In the standard mounting configuration (Fig.7), the roll motor readily provides capability for roll-axis forced oscillation testing. With combinations of sting extensions, mount variations, and yaw axis C-strut positioning, forced oscillation testing in the pitch and yaw axes are also possible. Those mounting schemes are illustrated in Fig. 8 and Fig. 9. Although the strut roll motor is capable of single axis arbitrary motion, only sinusoidal motions have been used during dynamic stability tests with the GTT.

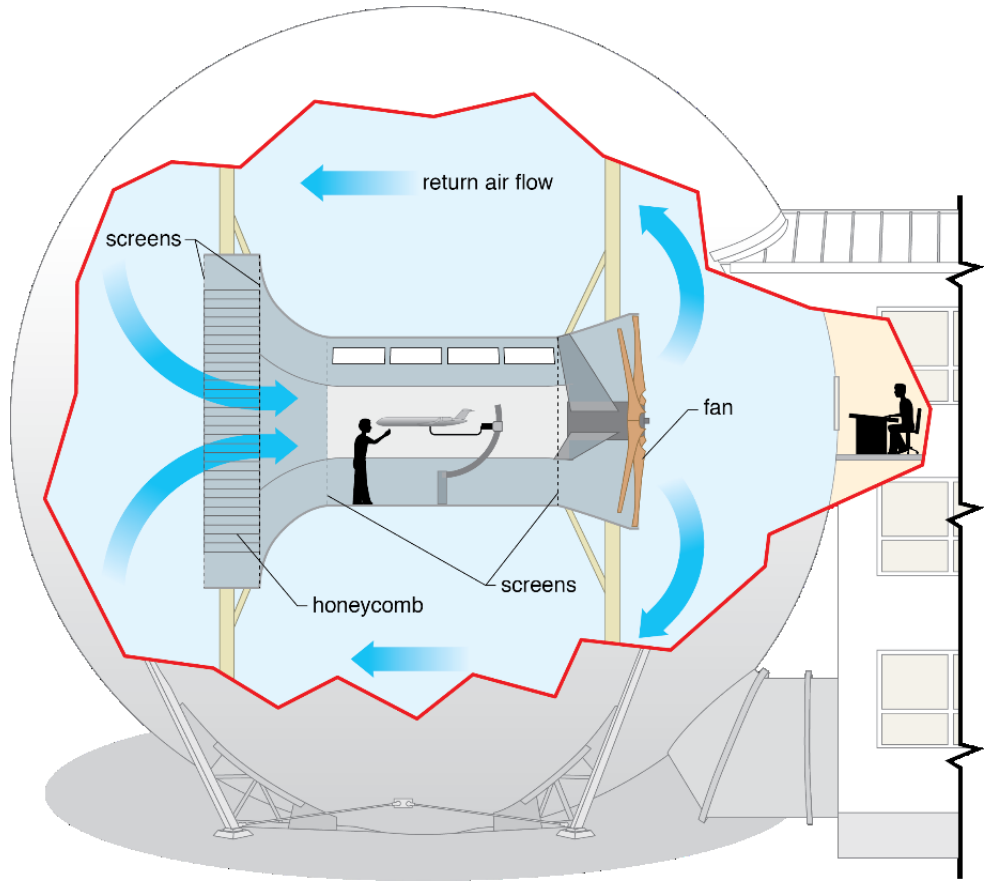

Fig. 7 The GTT is illustrated in the 12-Foot LST in the nominal mounting configuration used for static and roll-axis forced oscillation testing. 


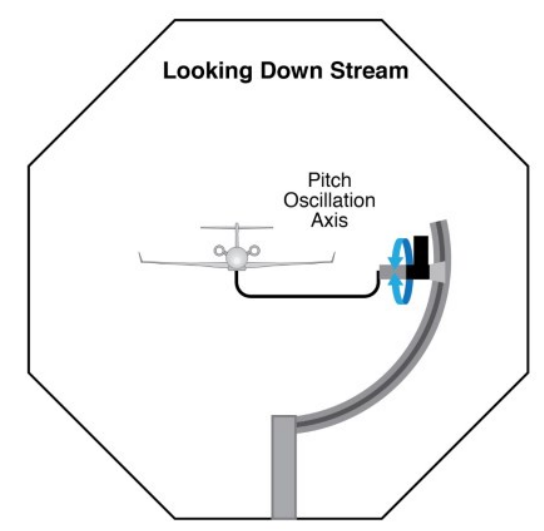

Fig. 8 The GTT is illustrated in the 12-Foot LST in the nominal mounting configuration used for pitch-axis forced oscillation testing.

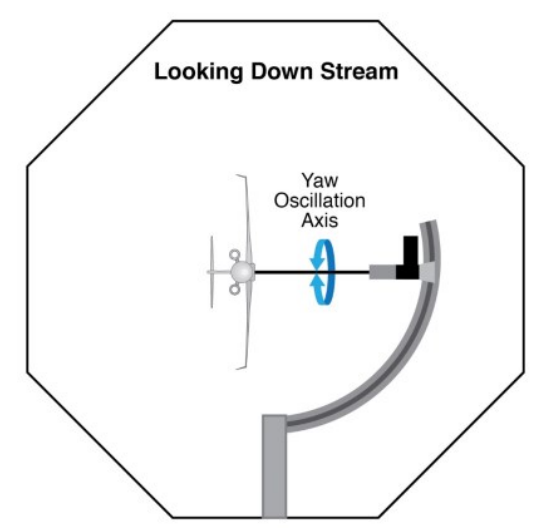

Fig. 9 The GTT is illustrated in the 12-Foot LST in the nominal mounting configuration used for yaw-axis forced oscillation testing.

\section{B. Boeing North American Aviation Research Tunnel (NAART)}

The BR\&T NAART is a low cost atmospheric pressure, open circuit tunnel generally used for exploratory and configuration refinement studies. The facility is capable of static force and moment testing in addition to traditional wind tunnel flow visualization techniques. The test section is 40 inches wide, 28 inches high, and 96 inches long. The tunnel is capable of operating at a maximum dynamic pressure of 65 pounds per square foot. The facility is shown in Fig. 10.

GTT tests in the NAART facility were generally conducted at a dynamic pressure of 40 pounds per square foot (chord based Reynolds number of 270,000). During these runs, data were acquired over an angle of attack range from -12 to 60 degrees and a sideslip range of $+/-20$ degrees. Figure 11 shows the GTT mounted in the NAART using an aft end straight sting. That sting and mounting arrangement were used to maximize angle-of-attack range using that facility's model support system.

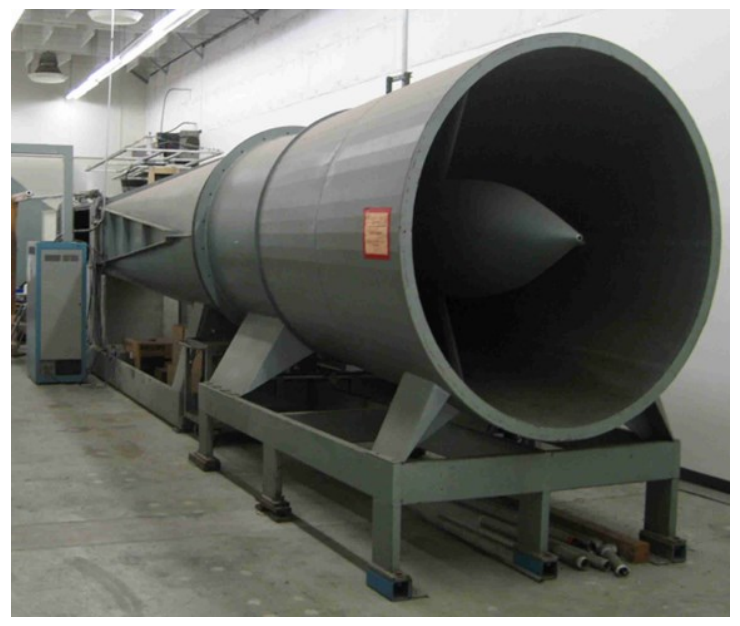

Fig. 10 The BR\&T NAART is pictured.

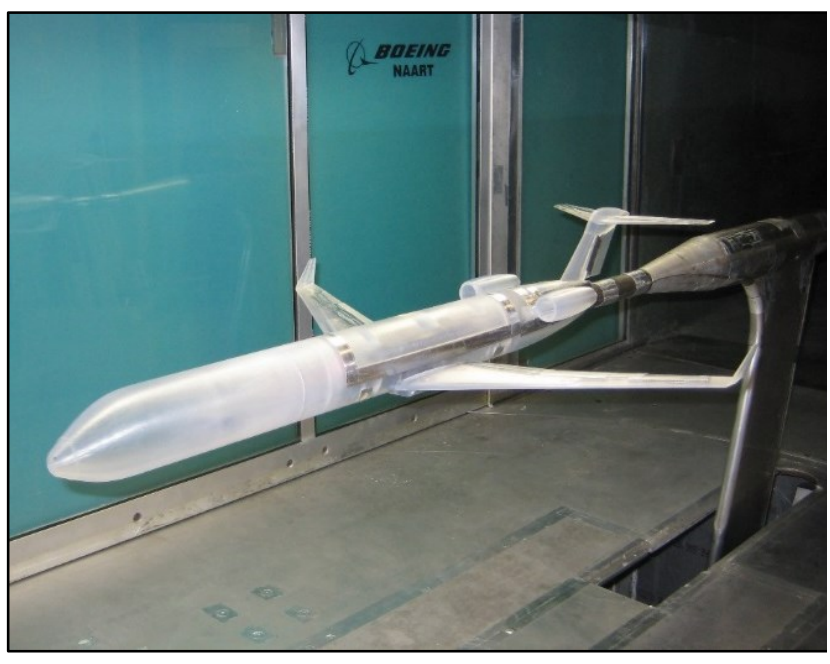

Fig. 11 The GTT configuration is shown mounted in the BR\&T NAART. 


\section{Boeing Research \& Technology Flow Visualization Water Tunnel (FVWT)}

The BR\&T FVWT is a closed-circuit water-tunnel facility located in the NAART wind-tunnel lab. The facility is capable of force and moment testing as well as flow visualization by injection of up to 6 colored dyes. The test section, which is open at the top to allow easy model access, is 24 inches wide, 36 inches high, and 72 inches long. The total capacity of the tunnel is approximately 5,000 gallons. The maximum flow velocity is 1 foot per second. Force and moment data were acquired by a 6-component submersible balance mounted in the model. The tunnel's motion control system allows data acquisition at static conditions or during programmed arbitrary motions.

Force and moment testing of the GTT configuration was performed at a water flow velocity of 1 foot per second (chord based Reynolds number of 20,000). Dye flow visualization tests were performed at a velocity of 0.25 feet per second (chord based Reynolds number of 5,000). A pitch offset arc was used to allow data to be acquired between -8 and 60 degrees angle of attack. A limited amount of data were acquired at non-zero angle of sideslip, which extended to $+/-16$ degrees. Although the motion control system is capable of arbitrary motion, due to schedule constraints, all dynamic stability testing was performed with single axis sinusoidal motion.

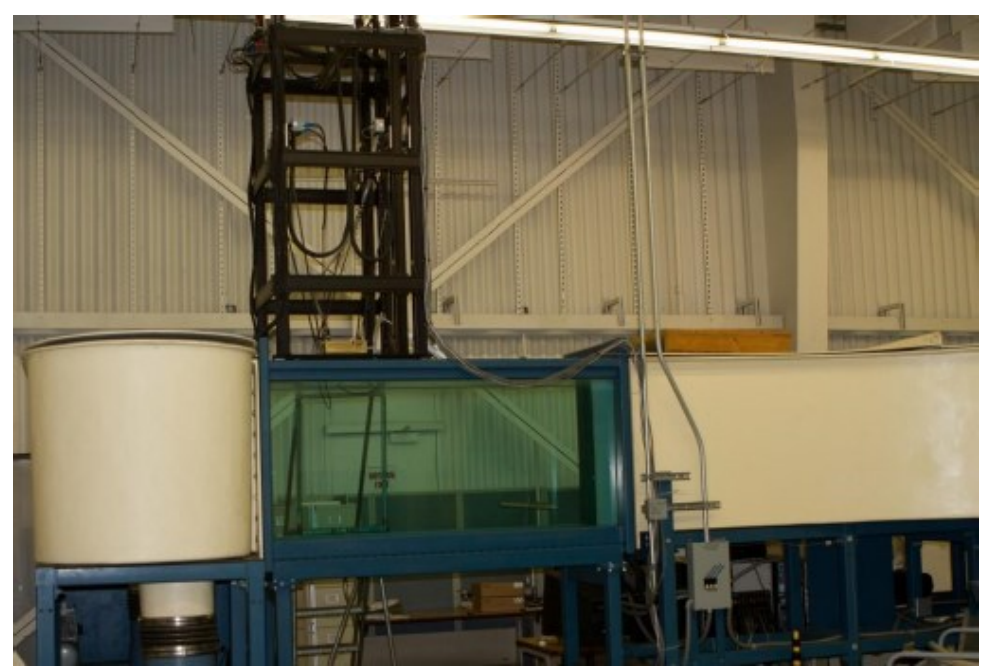

Fig. 12 The BR\&T FVWT is pictured. The black structure above the test section is part of the motion control rig.

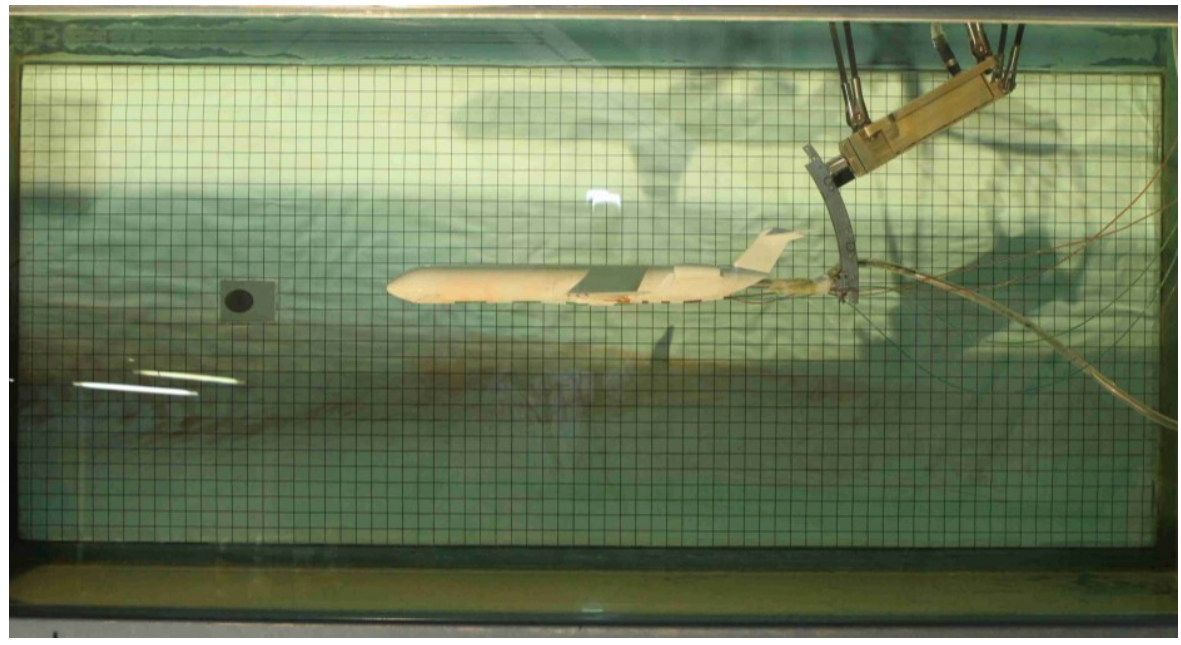

Fig. 13 The GTT configuration is shown mounted in the BR\&T FVWT. 


\section{NASA Computational Solutions}

A tetrahedral grid was generated for the GTT configuration using the VGRID code ${ }^{9,10}$. VGRID is a tetrahedral grid generator based on the advancing front method (AFM) for generation of surface triangles and "inviscid" field cells, and the advancing layers method (ALM) for generation of thin-layered "viscous" cells. Both techniques are based on marching processes in which tetrahedral cells grow from an initial front (triangular surface mesh) until the volume around the geometry is filled. Unlike the conventional AFM, which introduces cells into the field in a totally unstructured manner, the ALM generates organized layers of thin tetrahedral cells, one layer at a time, while maintaining the flexibility of AFM. VGRID input files are generated by an interactive geometry manipulation program, GridTool ${ }^{11}$. This graphics tool can import surface definitions from initial graphics exchange specification files containing non-uniform rational B-spline surfaces and curves, as well as PLOT3D point definition files. GridTool is used to manipulate the geometry and to define necessary geometric surface patches and grid spacing (source) parameters. The grid shown in Fig. 14 was generated in half-span with 28.75 million tetrahedral cells, and then mirrored to form a full-span grid with 57.5 million cells.

The computations for the GTT configuration were performed with the USM3D flow solver ${ }^{12}$ that is part of the NASA Tetrahedral Unstructured Software System (TetrUSS) ${ }^{13,14}$. USM3D is a parallelized tetrahedral cell-centered, finite volume compressible Reynolds-Averaged Navier-Stokes flow solver. Inviscid flux quantities are computed across each tetrahedral cell face using various upwind schemes. Spatial discretization is accomplished by a novel reconstruction process, based on an analytical formulation for computing solution gradients within tetrahedral cells. The solutions were run with a second-order physical time-step scheme. Several turbulence models are available in USM3D, but the one-equation Spalart-Allmaras model was used for these computations.

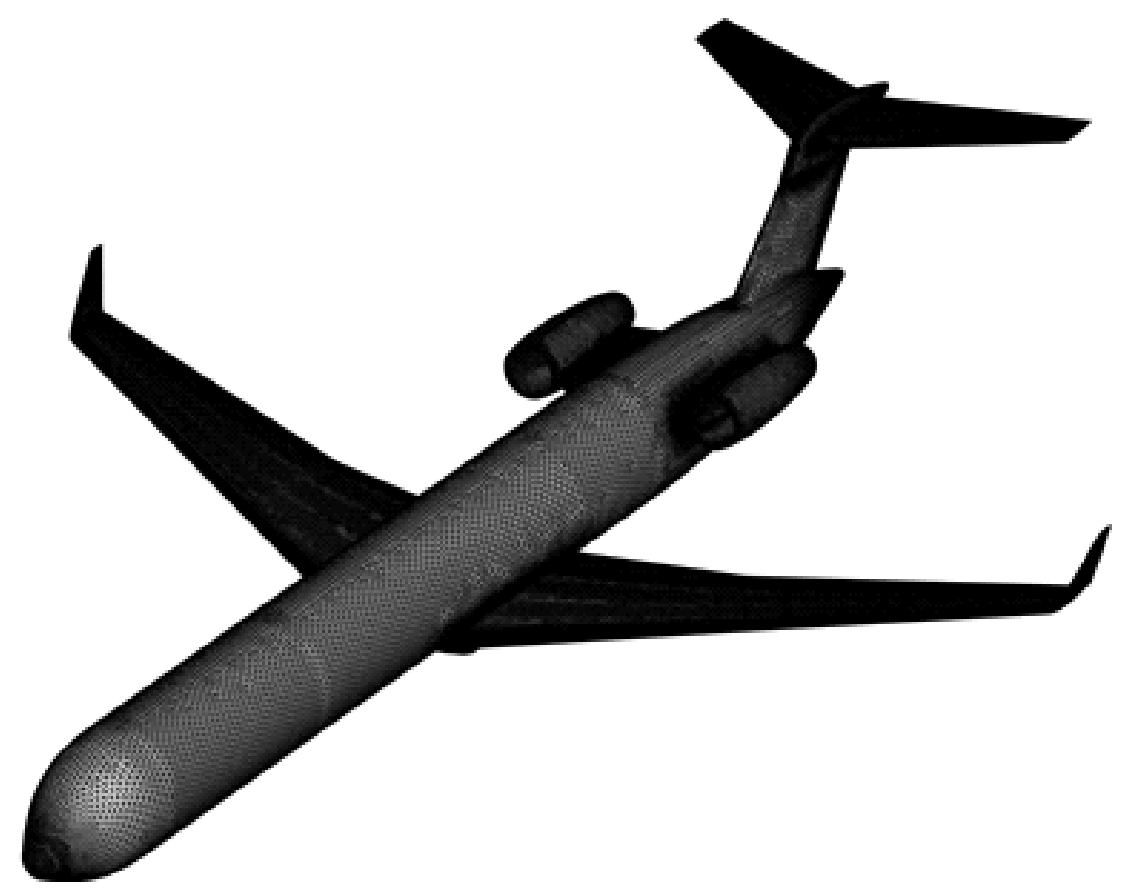

Fig. 14 The surface mesh for the GTT configuration is shown. The volume grid contains 57.5 million tetrahedral cells. 


\section{Dynamic Stability Data Reduction Method}

There are multiple methodologies to estimate the dynamic stability characteristics of an airplane from wind tunnel measurements. For this reason, the "single point" method used to produce the data shown in this publication will be briefly explained. Although this discussion will focus on the 12-Foot LST setup and methodology, it is still applicable to the data acquired in the BR\&T FVWT.

The primary dynamic stability parameters of interest in this work are the damping parameters. Because the forced oscillation motions used in this work were sinusoids, the damping parameters are a combination of effects from pure body axis rotation rate $(\mathrm{p}, \mathrm{q}$, or $\mathrm{r})$ and velocity vector rotation rate $(\dot{\alpha}$ or $\dot{\beta})$. The damping parameters of interest are:

$$
\begin{gathered}
\overline{C m_{q}}=C m_{q}+C m_{\dot{\alpha}} \\
\overline{C l p}=C l_{p}+C l_{\dot{\beta}} \sin (\alpha) \\
\overline{C n r}=C n_{r}-C n_{\dot{\beta}} \cos (\alpha) .
\end{gathered}
$$

In the GTT test entries to date, the data acquired for the purpose of dynamic stability assessment used motion control rigs to move the model with preprogrammed motion perturbations. The motions were performed about a reference angle of attack and angle of sideslip. The motions were sinusoidal at a constant frequency and amplitude. During the motions, force and moment data from the balance were recorded. In the 12-Foot LST test, balance data were recorded at 250 Hertz. To estimate the aerodynamic effect of the oscillatory motion at each reference condition, 40 cycles of data were recorded with wind on and 20 cycles of data were recorded with wind off for use as a tare. A two-pass Butterworth filter scheme was used to condition the signal while minimizing phase shift. The filter cutoff frequency was 4 times the oscillatory frequency.

The signal-conditioned force and moment data were used to construct hysteresis loops with respect to the oscillation angle. Data from each loop were interpolated onto a common set of angular points (1,000 points per cycle). The interpolated data from each of the 40 cycles were used to compute an ensemble average cycle. Figure 15 illustrates this for pitch axis forced oscillations using the GTT. In this figure, $\mathrm{q}_{\min }$ and $\mathrm{q}_{\max }$ mark the points in the loop where the perturbation loop crosses zero. At these points, for a theoretical perfect sinusoidal motion, angular acceleration will be zero and angular rates will be at a maximum or minimum. For the single point method, the stability derivative (change in coefficient with respect to change in rate) is computed by calculating the ratio of the force or moment coefficient difference to the non-dimensional rate difference at that single point. Equation 4 illustrates how the pitch damping parameter would be calculated using single point method with the points shown in Fig. 15. The damping parameters for the roll and yaw axes would be calculated in an analogous manner.

$$
\overline{C m_{q}}=\frac{C m_{\text {at qmin }}-C m_{\text {at } q \max }}{\frac{C}{2 V}\left(q_{\min }-q_{\max }\right)}
$$

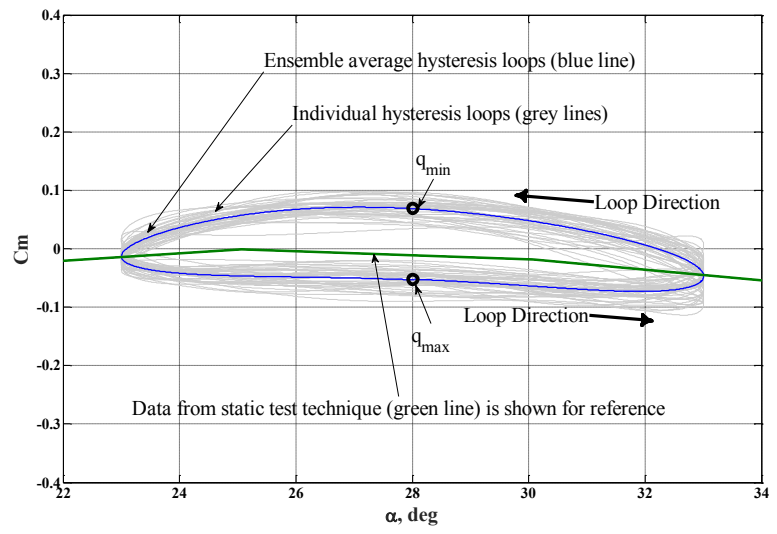

Fig. 15 Hysteresis loop of pitching moment data for pitch-axis sinusoidal forced oscillation at 5 degree amplitude about a 28 degree angle of attack. (Note: these pitching moment data are referenced to the balance reference center, $34.4 \%$ mean aerodynamic chord.) 


\section{Results}

Preliminary results of various tests relating to the stall and post-stall characteristics of the GTT configuration are discussed herein. The NASA Langley 12-Foot LST was the primary test facility used for this work. Because the 12Foot LST is a low-cost research tunnel which is generally used for preliminary studies, data from other sources were acquired, analyzed, and compared to verify and enhance information obtained from the primary source. Unless otherwise annotated, data presented here are from the 12-Foot LST facility.

\section{A. Flow Visualization}

All physical flow visualization testing (to date) has been performed in the FVWT facility. All flow visualization from computational methods have been generated with the NASA TetrUSS/USM3D solver. The purpose of the flow visualization was to gain confidence in - and a better understanding of - static and dynamic force and moment measurements that were already acquired. The primary purpose of the model used in the FVWT tunnel was to obtain data using forced oscillation test techniques. Thus, it was not designed with built-in dye ports. Hence, the flow visualization testing was performed using a dye wand and for a limited case, with tubes attached externally to the model.

To visualize separated flow off the wing, three dye tubes were attached to the underside of the wing such that dye flow was entrained over the leading edge and into the separated flow. Figure 16 illustrates this for 14 degrees angle of attack. A pitch-pause angle of attack sweep showed the horizontal stabilizer to be within the low-energy, separated wake between 20 and 35 degrees angle of attack. Key findings of this (attached dye tube study) were verified with a dye wand survey after all external dye tubes were removed from the model. To assess the relevance of this water tunnel result to a full scale vehicle at flight (chord based) Reynolds number, USM3D solutions were analyzed. Figure 17 illustrates a comparable result at 13 degrees angle of attack and 16 million chord based Reynolds number. In the figure, Mach number is contoured. Dark (blue) colors signify the very low energy separated flow, which is shown interacting with the engine nacelle inlet.

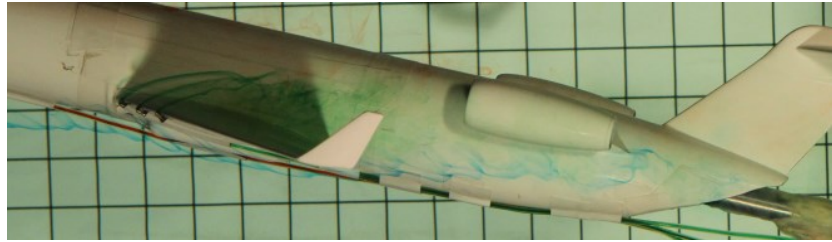

Fig. 16 Photo from FVWT showing separated wing wake (green dye) interacting with left engine inlet at 14 degrees angle of attack.

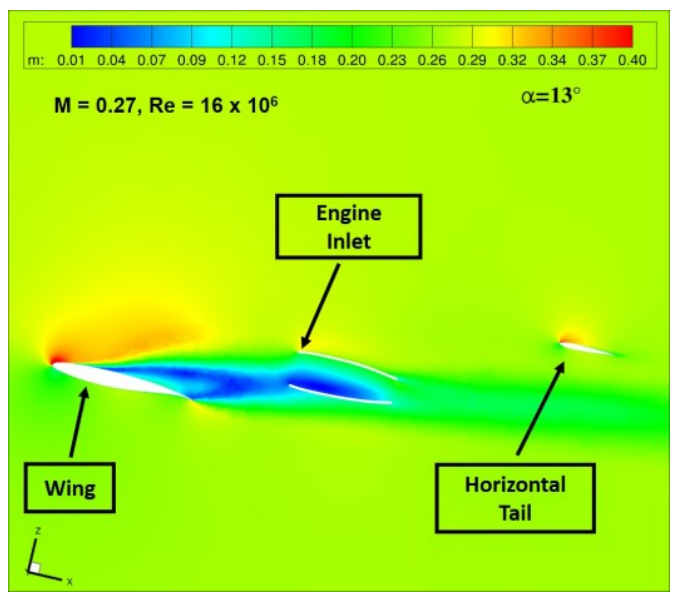

Fig. 17 Mach number contours, from a CFD solution, showing interaction of low energy wake with left engine nacelle at a 13 degrees angle of attack condition 
Additional flow visualization studies of the fuselage were performed using a forked dye wand which produced parallel, laterally offset, red and blue dye streams. The wand was positioned to symmetrically flow the dye over the forward fuselage. Consistent with CFD prediction, two vortex sheets were observed to form on the forward fuselage, which is illustrated in Fig. 18. In the FVWT test, the vortex structures were found to form at 16 degrees angle of attack, exhibit excellent left/right symmetry, and remain generally close to the fuselage until bursting at a body station location forward of the engine inlet. The burst point was observed to shift forward slightly with increasing angle of attack. The burst point location was generally consistent with the vortex flow interacting with the separated wing wake. The good left/right symmetry was observed until angle of attack reached 35 degrees. At angle of attack above 35 degrees, the vortex structures were observed to become significantly larger in diameter, further off body, and become less symmetric as angle of attack further increased. The asymmetry was observed to reach an apparent maximum at 50 degrees angle of attack.

A detailed study of vortex symmetry conditions was performed at 50 degrees angle of attack. During this study, yawing moment and side force was measured during two sideslip sweeps between -8 and +8 degrees. The initial position and direction of the sweep was changed between those two runs. The sweep rate was 0.5 degrees per second in both cases. The initial and final vortex states were visualized. Figures 19 to 21 illustrate the vortex asymmetry and corresponding measured yawing moment coefficient. The state in Fig. 19 correlated to the nose right (positive) yawing moment shown in Fig. 20. Similarly, Fig. 21 illustrates the structure that was observed for negative yawing moment. During multiple repeat static points at zero degrees sideslip (and 50 degrees angle of attack) both vortex states were observed. Although not shown, the side force measurements were consistent with yawing moment sign and trend.

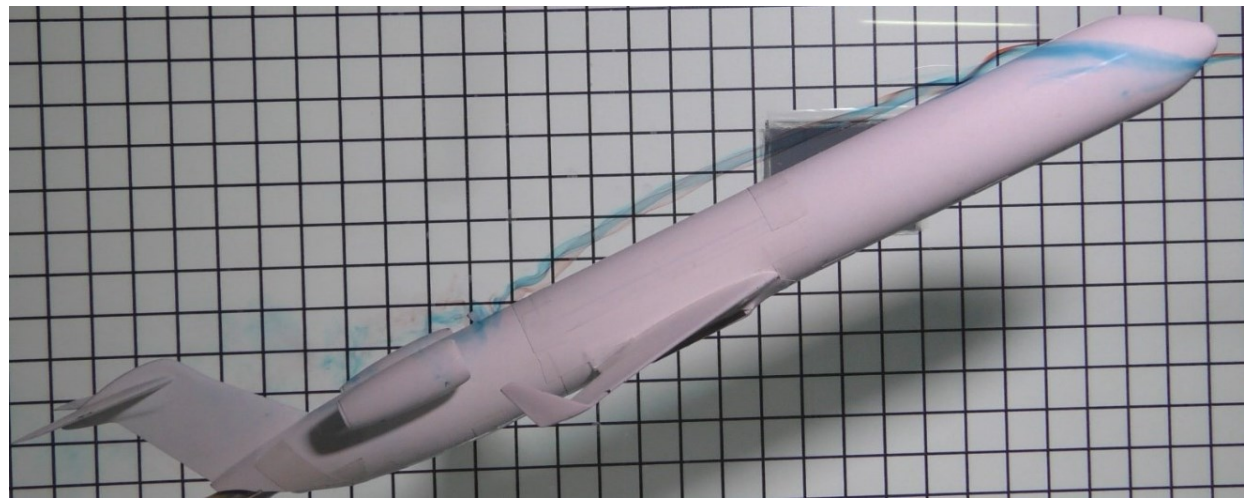

Fig. 18 Flow visualization photo of fuselage vortex at 24 degree angle of attack. Symmetric left (red dye) and right (blue dye) vortex sheets are shown forming on top of the forward fuselage and bursting just forward of the engine inlet.

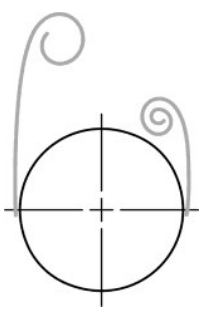

Fig. 19 Diagram of vortex structure observed at $\mathbf{5 0}$ degrees angle of attack and $\mathbf{- 8}$ degrees angle of sideslip (view perspective is looking forward / upstream).

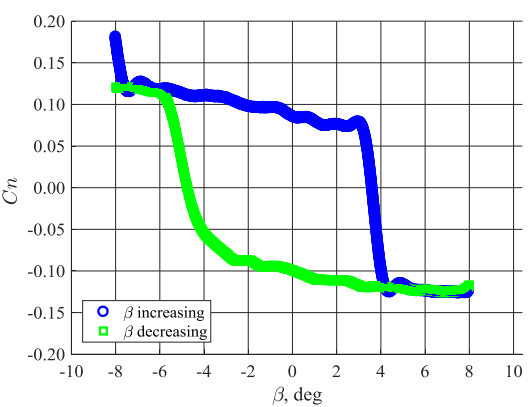

Fig. 20 Yawing moment coefficient variation with angle of sideslip during quasi static sideslip sweep performed at 50 degrees angle of attack (FVWT data).

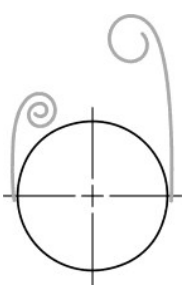

Fig. 21 Diagram of vortex structure observed at 50 degrees angle of attack and +8 degrees angle of sideslip (view perspective is looking forward / upstream). 


\section{B. Longitudinal Static Stability and Control Characteristics}

Select force and moment results from tunnel and CFD are presented. The purpose is to illustrate some of the stability and control characteristics that could be important in the development of simulation models to support training for pilot recognition and recovery from aerodynamic stall of the GTT configuration.

Pitching moment characteristics from tunnel and CFD sources are shown in Fig. 22. All data in the figure were acquired with all controls zero and referenced to a $25 \%$ mean aerodynamic chord location. All sources in the figure show stable static stability at low angle of attack, followed by an unstable pitch break of varying abruptness. The 12Foot LST and NAART tunnel both show a smooth transition from a stable to an unstable stability characteristic at 10 degrees angle of attack. Two pitching moment characteristics from CFD solutions are also shown in the figure - one run at a Reynolds number approximately the same as the tunnel tests and the other a Reynolds number that would be appropriate for a full scale vehicle. Both of the CFD characteristics show a small stability inflection at 10 degrees angle of attack followed by a more abrupt stability transition. For the low Reynolds number CFD solution, the initial unstable pitch break occurs at 12 degrees angle of attack. For the high Reynolds number CFD solution, the pitch break occurs at 16 degrees angle of attack. All sources are in general agreement at angles of attack above 18, with the exception of the 35 to 40 degree angle of attack region. There, the tunnel data shows slightly more static stability than the CFD solutions do. Overall, agreement of pitching moment variation with angle of attack is considered to be good.

Figure 23 shows the effect of full elevator deflection on the pitch moment characteristic (all other controls zero and moments referenced to $25 \%$ chord). The -20 degree elevator deflection case is significant for a scenario in which the pilot applies a full aft (aggravated) column input. That curve shows a static trim point at 35 degrees angle of attack. The baseline case, zero degrees elevator, shows that if the column were released and elevator returned to zero, there would be a sufficient nose down moment for (a static) recovery. Also of importance, the curve for elevator at +20 degrees deflection shows the critical angle of attack (where stall recovery nose down capability is a minimum) to be 35 degrees.

Figure 24 is similar to Fig. 23, with the exception that the pitching moment data have been shifted to represent a scenario of center of gravity at $40 \%$ chord. In this static case, for -20 degrees elevator, the trim angle of attack is shown to be 45 degrees. If the elevator were returned to zero degrees, the potential for a weak trim at 35 degrees angle of attack is shown. The data show that for full trailing edge down elevator (+20 degrees), there exists sufficient control effectiveness to create a nose down moment for recovery.

Finally, Fig. 25 shows that when the stabilizer is set to -10 degrees (aircraft nose up) and center of gravity is at $40 \%$ chord, a locked-in deep stall could result. Conversely, Fig. 23 and 24 indicate that static locked-in deep stall trim risk could be mitigated with center of gravity envelope limits and/or stabilizer limitations.

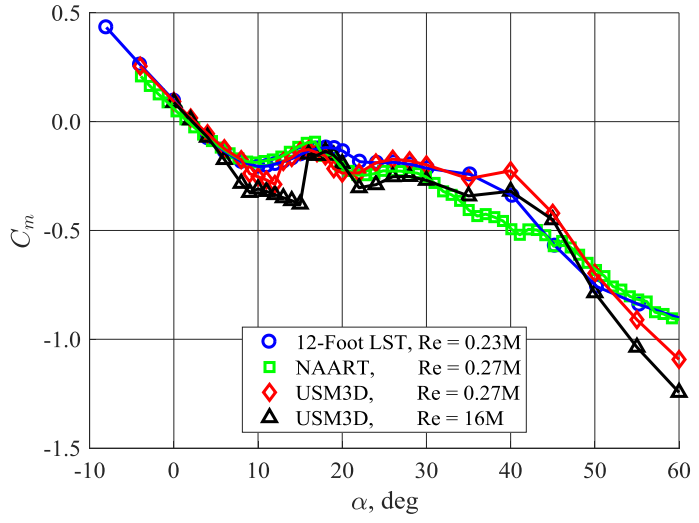

Fig 22 Pitching moment coefficient variation with angle of attack from different sources at several chord based Reynolds numbers.

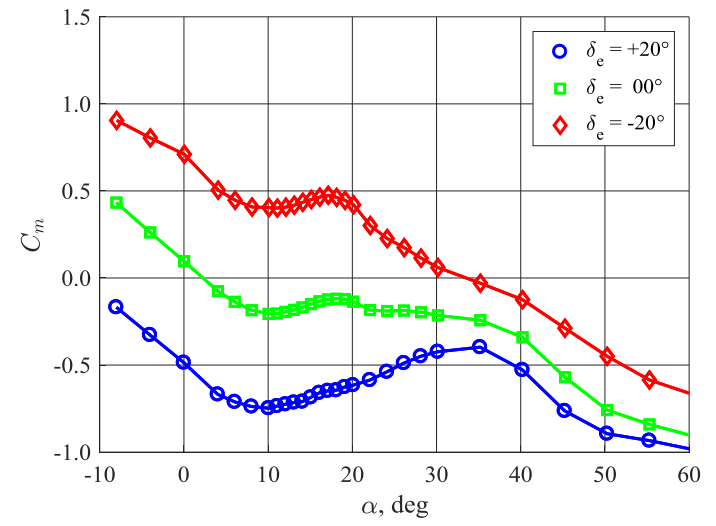

Fig. 23 Pitching moment coefficient variation with angle of attack for 3 elevator deflections (data from 12-Foot LST). 


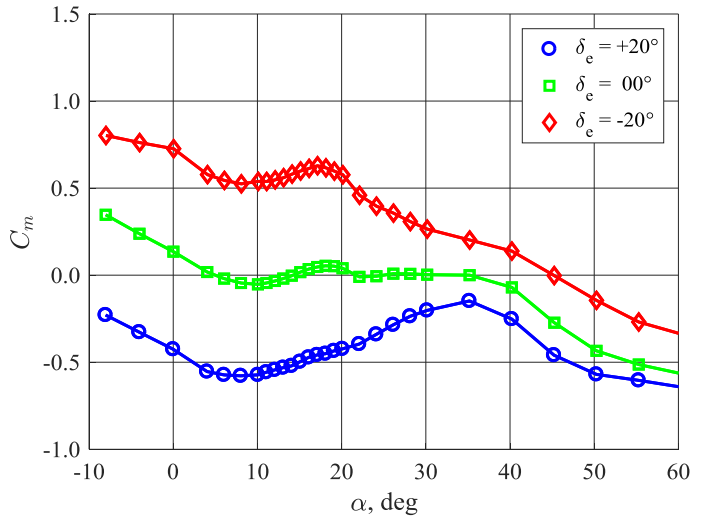

Fig. 24 Pitch control power for 0 degrees stabilizer and center of gravity at $40 \%$ mean aerodynamic chord (data from 12-Foot LST).

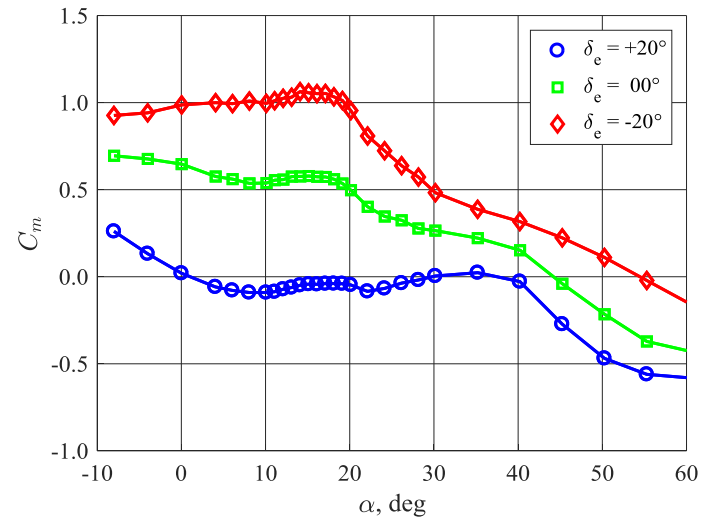

Fig. 25 Pitch control power for -10 degrees stabilizer and center of gravity at $40 \%$ mean aerodynamic chord (data from 12-Foot LST).

\section{Lateral and Directional Static Characteristics}

Select force and moment results from the 12-Foot LST are presented for the model configured with the 1.5 degree dihedral wing. The purpose is to illustrate some of the stability and control characteristics for this configuration and how those characteristics varied at high wind incidence angles.

Variation of the lateral and directional static stability derivatives $C l_{\beta}$ and $C n_{\beta}$ with angle of attack is shown in Fig. 26. These derivatives were computed by linear differencing between +4 and -4 degrees sideslip. Both derivatives indicate stable static stability in the normal, low angle of attack range. As angle of attack increases, the lateral static stability derivative remains stable (negative value). However, the directional static stability derivative begins decreasing at 10 degrees angle of attack and becomes unstable above 20 degrees angle of attack. This is attributed to the increasing effect of upstream separated flow interacting with the vertical tail.

The lateral and directional moment characteristics are shown in Fig. 27 and 28 respectively. In these figures, static stability is indicated by an increase in the magnitude of the respective moment as sideslip angle increases. In Fig. 27, a stable, restoring rolling moment is maintained over the angle of attack range (negative values of $C_{l}$ ). Local lateral stability (the change in moment with respect to the change in local sideslip angle) is generally maintained over the angle of attack range. However, at high angles of sideslip (20 to 30 degrees), the local lateral stability characteristics show significant nonlinearity and stability variation. Fig. 28 shows stable directional static stability characteristics at low angle of attack, with the exception of high sideslip angles (above 20 degrees sideslip). The figure also shows that at higher ( $>10$ degrees) angles of attack, local directional stability (and restoring moment) is progressively lost at all angles of sideslip.

Figure 29 shows the variation of the incremental effect of full roll control deflections with angle of attack. The curves in the figure show the effect of aileron deflection (right aileron 25 degrees trailing edge down and left aileron 25 degrees trailing edge up), roll spoiler (all spoilers up 60 degrees on left wing), and measurement of the effect of both aileron and roll spoilers deflected simultaneously. Control effectiveness begins to decrease at a slightly lower angle of attack for the ailerons than it does for the spoiler. Both ailerons and spoilers reach minimum effectiveness by 14 degrees angle of attack. The figure also shows that superposition of the aileron and spoiler effect would agree well with the measurement of the combined effect.

Figure 30 shows the variation in the incremental effect of various rudder deflections with angle of attack. Good linearity with deflection is seen for rudder effectiveness. Above 20 degrees angle of attack, the effectiveness decreases to near zero. The apparent spike in effectiveness at 50 degrees is considered false, and is attributed to run-to-run fluctuations in yawing moment asymmetry.

Figure 31 shows yawing moment variation with angle of attack for zero degrees sideslip for the FVWT, 12-Foot LST, and NAART tunnels. This figure shows that for all three facilities (and different models) there was a consistent development of a large yawing moment asymmetry at about 40 degrees angle of attack. Although the asymmetry was discussed in the flow visualization section for the FVWT (which had the largest yawing moment asymmetry), the asymmetries measured in the other facility were still of a magnitude significantly higher than the available rudder control effectiveness. 


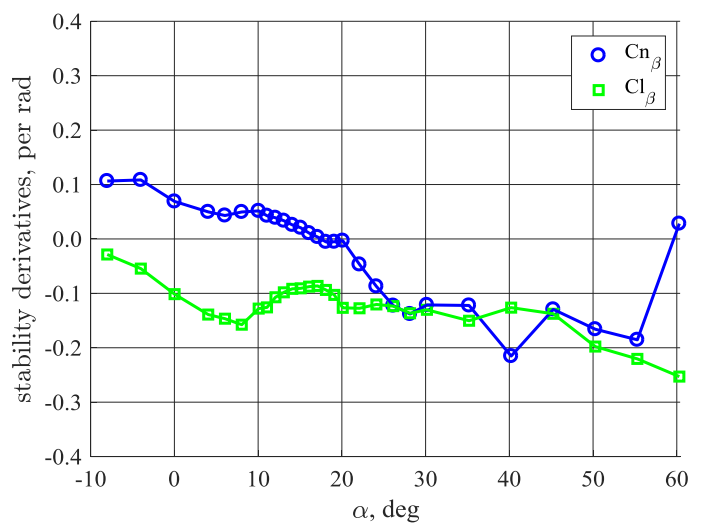

Fig. 26 Lateral and directional static stability derivatives $\left(C l_{\beta}<0=>\right.$ stable, $C n_{\beta}>0=>$ stable; data from 12-Foot LST)

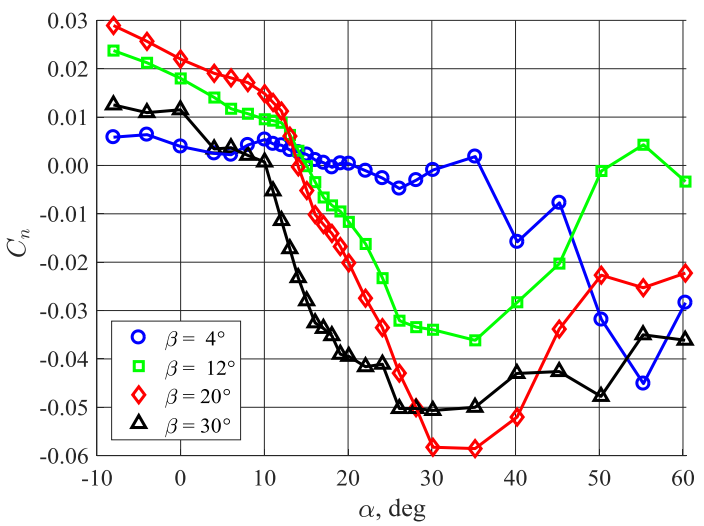

Fig. 28 Variation of directional static stability characteristics with angle of attack (12-Foot LST data).

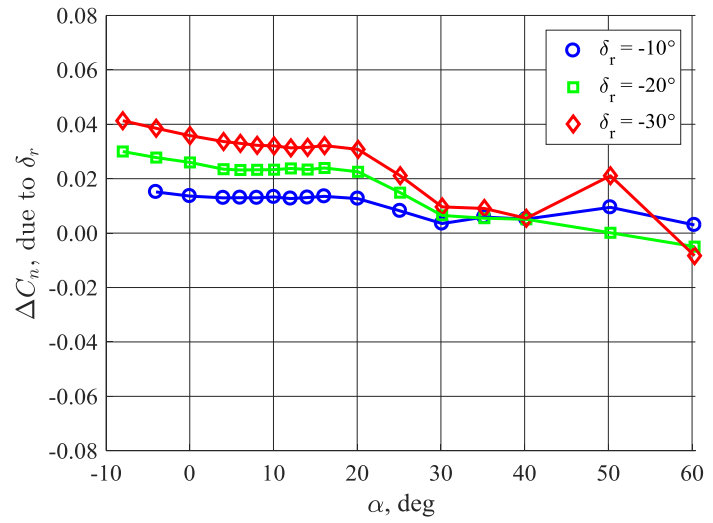

Fig. 30 The change in yawing moment due to rudder deflection over an angle of attack range (12Foot LST data).

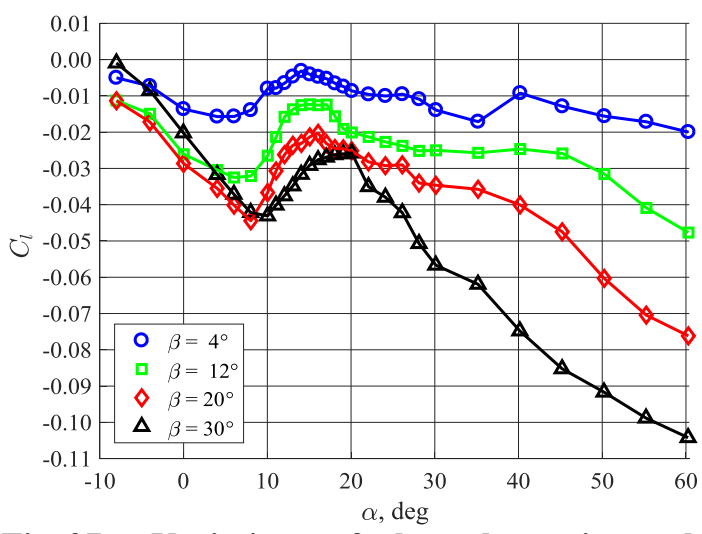

Fig. 27 Variation of lateral static stability characteristics with angle of attack (12-Foot LST data).

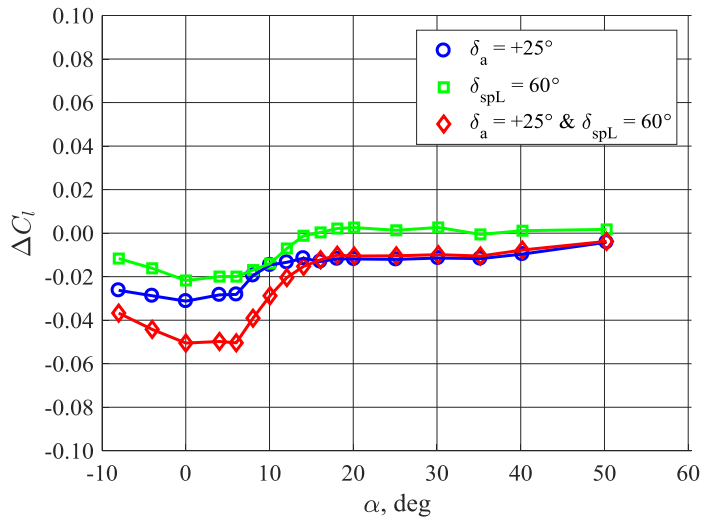

Fig. 29 Roll control effectiveness is shown for aileron and roll spoiler deflection (12-Foot LST data).

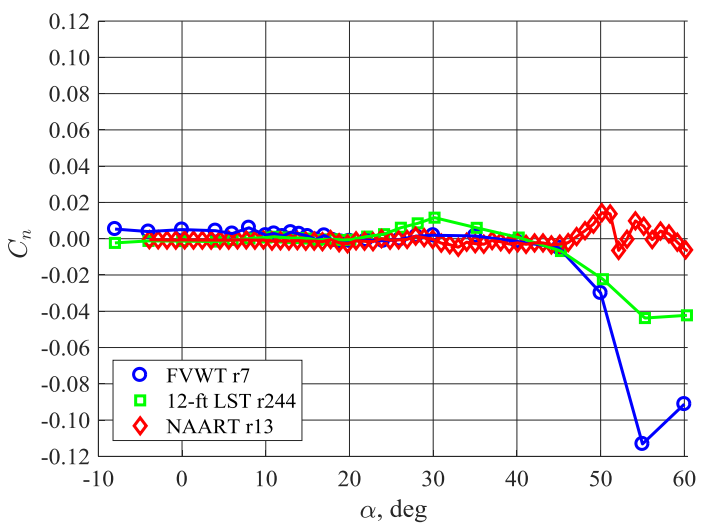

Fig. 31 Yawing moment asymmetry at zero sideslip angle. 


\section{Dynamic Stability Characteristics}

Dynamic stability coefficients were estimated using the forced oscillation test technique ${ }^{15}$. The derivatives of primary interest were the pitch, roll, and yaw body axis damping derivatives. The initial results are shown in Fig. 32 to 34. They were obtained during runs using sinusoidal oscillations at constant frequencies and amplitude. The scaled frequencies were based on the frequencies of classic dynamic modes (Short Period and Dutch Roll). The reduced frequency, $k=\left(\omega L_{-} r e f\right) / 2 \mathrm{~V}$, was 0.0158 for the pitch axis oscillations and 0.094 for the roll and yaw axis oscillations. The characteristic length, $\mathrm{L}_{\text {ref, }}$ was the mean aerodynamic chord for the pitch axis oscillations, and wingspan for the lateral and directional axis oscillations. The amplitude of oscillation for the pitch axis was 5 degrees. The amplitude of body axis oscillations used in the roll and yaw axes was 10 degrees. The data shown in Fig. 32 to 34 were all reduced using the single point method. These data should, in general, be considered preliminary because further analysis and modeling using more advanced techniques is planned. Note that unstable damping is indicated by coefficient values greater than zero.

Figure 32 shows a good comparison between 12-Foot LST data and FVWT data for angle of attack less than 50 degrees. It is also seen that (for this frequency and amplitude of oscillation) as angle of attack increases, after a rapid reduction in pitch damping, it quickly returns to nominal level. In general, the pitch damping is less than a nominal level of -40 per radian only between 15 and 22 degrees angle of attack.

Figure 33 shows good comparison between 12-Foot LST data and FVWT data for angle of attack less than 35 degrees. A roll damping stability derivative value of about -0.4 per radian is shown at normal slow cruise angle of attack. The roll damping quickly decreases as angle of attack increases above 6 degrees. Neutral to slightly unstable roll damping is indicated at and above 10 degrees angle of attack. The roll damping remains low to unstable over a wide angle of attack range above 20 degrees.

Figure 34 shows good yaw damping data comparison between 12-Foot LST and CFD-derived forced oscillation results below 26 degrees angle of attack. Good agreement is seen between the 12-Foot LST and FVWT data below 20 degrees. Above 25 degrees angle of attack, good agreement is seen between the CFD data and the FVWT data. Note that in the 12-Foot LST, the yaw axis forced oscillation tests were only performed to a maximum to 30 degrees angle of attack. This limit is due to the expectation of aerodynamic interference between the model support system and tail of the model at angle of attack above 30 degrees. This is an artifact of the mounting configuration used for yaw axis forced oscillation testing at very high angle of attack. In Fig. 9, it can be seen that to achieve positive angle of attack, the model support system must rotate the c-strut upstream. The tail of the model would then rotate to approach alignment with the c-strut as angle of attack is increased. The shift of the CFD data away from the 12-Foot LST data (at 26 degrees angle of attack) is hypothesized to be due to this aerodynamic interference. Further testing is planned using an alternate (top) mount technique to attempt further investigate the interference. Significantly unstable (indicated by positive coefficient values) yaw damping is indicated between 30 and 42 degrees angle of attack.

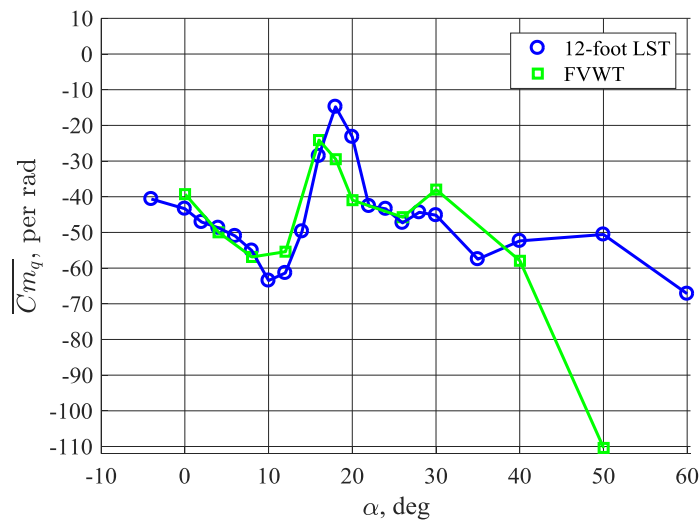

Fig. 32 Variation of the pitch damping parameter with angle of attack (oscillation amplitude $=5$ degrees, $\mathrm{k}=\mathbf{0 . 0 1 5 8}$ ).

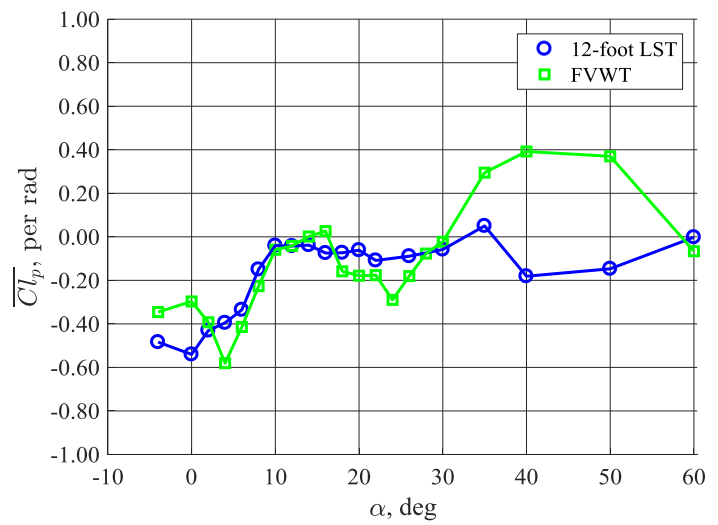

Fig. 33 Variation of the roll damping parameter with angle of attack (oscillation amplitude $=10$ degrees, $k=0.094)$. 


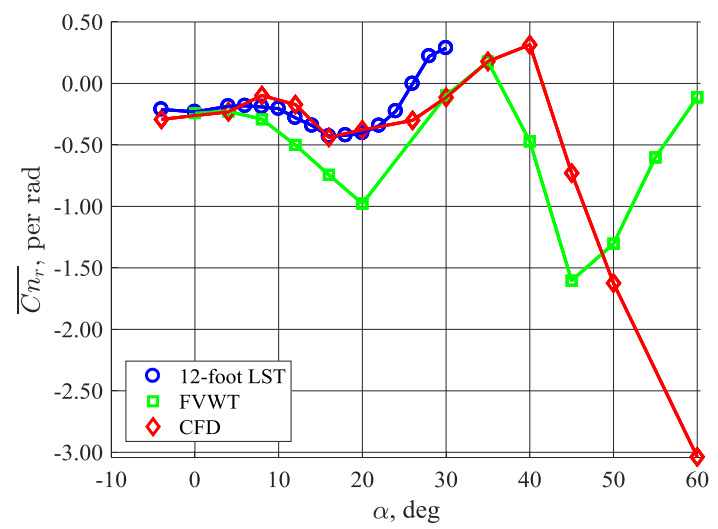

Fig. 34 Variation of the yaw damping parameter with angle of attack (oscillation amplitude $=10$ degrees, $k=0.094)$.

\section{Concluding Summary}

Various ground-based test techniques have been used to analyze stability and control characteristics of a generic T-tail transport airplane configuration. The purpose of the testing was to develop simulations to study model fidelity requirements that are appropriate for training pilots to recognize and recover from stall in a T-tail transport airplane. The tunnel test techniques that have been used in this work include flow visualization, static force and moment measurement, and sinusoidal forced oscillation force and moment measurement. These results have been augmented by flow visualization, as well as static and dynamic force and moment calculations from CFD static and dynamic simulations.

Significant findings include:

- unstable pitch break at 10 degrees angle of attack (based on low Reynolds number tunnel measurements)

- abrupt unstable pitch break at 16 degrees angle of attack (based on CFD results at flight Reynolds number)

- absence of a locked-in deep stall static trim point for $25 \% \mathrm{CG}$

- presence of a locked-in deep stall static trim point for $40 \%$ CG with -10 degrees nose-up stabilizer trim

- unstable body axis directional static stability above 18 degrees angle of attack

- significant reductions in dynamic stability at angles of attack above 10 degrees

- significant reductions in control effectiveness at post-stall angles of attack

- $\quad$ significant post-stall asymmetries

- correlation of large directional asymmetry and hysteresis with asymmetric vortex arrangements on the forward fuselage at 50 degrees angle of attack

- separated wing wake interaction with engine nacelle inlets at approximately 14 degrees angle of attack.

Additional work should include additional analysis and testing to formulate more robust dynamic stability models for angles of attack above 40 degrees (where large asymmetries and hysteresis were noted). Additional testing and analysis should be conducted to assess the effect of frequency, rate, and oscillation amplitude on dynamic stability characteristics. Additional static and dynamic test should be conducted to assess component effects on key stability characteristics.

\section{Acknowledgements}

The authors would like to thank Kevin Davis, Clinton Duncan, Sue Grafton, Earl Harris, Jeff Jonokuchi, Justin Petrilli, and Lee Pollard and for their significant contributions to this work. 


\section{References}

1"Statistical Summary of Commercial Jet Airplane Accidents: Worldwide Operations 1959-2015.", Boeing Commercial Airplanes. Seattle, Washington, July 2016

${ }^{2}$ Shah, Gautam H., et al., "Wind-Tunnel Investigation of Commercial Transport Aircraft Aerodynamics at Extreme Flight Conditions", SAE World Aviation Congress \& Display, SAE Paper 2002-01-2912, November, 2002.

${ }^{3}$ Foster, John V., et al., "Dynamics Modeling and Simulation of Large Transport Airplanes in Upset Conditions", AIAA Guidance, Navigation, and Control Conference, AIAA Paper 2005-5933, August, 2005.

4"'Loss of Control on Approach, Colgan Air, Inc., Operating as Continental Connection Flight 3407, Bombardier DHC-8-400, N200WQ, Clarence Center, New York, February 12, 2009," Accident Report NTSB/AAR-10/01, National Transportation Safety Board, Washington DC, Feb. 2010.

${ }^{5}$ Schroeder, Jeffery A. and Burke, Robert H., "Upset Prevention and Recovery Training - A Regulator Update", AIAA Modeling and Simulation Technologies Conference, AIAA Paper 2016-1429, January, 2016.

${ }^{6}$ Schroeder, Jeffery A., et al., "An Evaluation of Several Stall Models for Commercial Transport Training”, AIAA Modeling and Simulation Technologies Conference, AIAA Paper2014-1002, January, 2014.

${ }^{7}$ Kuehme, D., Alley, N., Phillips, C, Cogan, B., "Flight Test Evaluation and System Identification of the Area-I PrototypeTechnology-Evaluation Research Aircraft (PTERA)", AIAA Flight Testing Conference, AIAA Paper 2014-2577, January, 2014.

${ }^{8}$ Belcastro, Christine M.., et al., "Aircraft Loss of Control Problem Analysis and Research Toward a Holistic Solution", Journal of Guidance, Control, and Dynamics, Vol. 40, No. 4, 2017, pp. 733-775.

${ }^{9}$ Pirzadeh, S. Z., "Three-Dimensional Unstructured Viscous Grids by the Advancing Layers Method," AIAA Journal, Vol. 34, No. 1, 1996, pp. 43-49. doi:10.2514/3.13019

${ }^{10}$ Pirzadeh, S. Z., “Advanced Unstructured Grid Generation for Complex Aerodynamic Applications,” AIAA Journal, Vol. 48, No. 5, 2010, pp. 904-915. doi:10.2514/1.41355

${ }^{11}$ Samareh, J., "GridTool: A Surface Modeling and Grid Generation Tool," Proceedings of the Workshop on Surface Modeling, Grid Generation, and Related Issues in CFD Solutions, NASA CP-3291, 1995.

${ }^{12}$ Frink, N. T., "Tetrahedral Unstructured Navier-Stokes Method for Turbulent Flows," AIAA Journal, Vol. 36, No. 11, 1998, pp. 1975-1982. doi:10.2514/2.324

${ }^{13}$ Frink, N. T., Pirzadeh, S. Z., Parikh, P. C., Pandya, M. J., and Bhat, M. K., "The NASA Tetrahedral Unstructured Software System (TetrUSS),” Aeronautical Journal, Vol. 104, No. 1040, 2000, pp. 491-499.

${ }^{14}$ Pandya, M. J., Frink, N. T., Abdol-Hamid, K. S., Samareh, J. A., Parlette, E. B., and Taft, J. R., "Enhancements to TetrUSS for NASA Constellation Program,” Journal of Spacecraft and Rockets, Vol. 49, No. 4, 2012, pp. 617-631. doi: 10.2514/1.A32089

${ }^{15}$ Owens, D. Bruce., et al., "Overview of Dynamic Test Techniques for Flight Dynamics Research at NASA LaRC", $25^{\text {th }}$ AIAA Aerodynamic Measurement Technology and Ground Testing Conference, AIAA Paper 2006-3146, June, 2006. 